\title{
Interprofessional Collaboration and Smartphone Use as Promising Strategies to Improve Prenatal Oral Health Care Utilization among US Underserved Women - Results from a Qualitative Study
}

\section{Lin Wang}

University of Rochester Medical Center

Johana Ren

University of Rochester

Kevin Fiscella

University of Rochester Medical Center

Sherita Bullock

Healthy Baby Network

Mechelle R Sanders

University of Rochester Medical Center

Elizabeth Loomis

University of Rochester Medical Center

\section{Eli Eliav}

University of Rochester Medical Center

\section{Michael Mendoza}

Monroe County Department of Public Health

\section{Rita Cacciato}

University of Rochester Medical Center

\section{Marie Thomas}

University of Rochester Medical Center

Dorota T Kopycka-Kedzierawski

University of Rochester Medical Center

Ronald J Billings

University of Rochester Medical Center

Jin Xiao ( $\nabla$ jin_xiao@urmc.rochester.edu )

Eastman Institute for Oral Health, University of Rochester Medical Center, Rochester, NY https://orcid.org/0000-0002-8776-2520 
Keywords: Prenatal oral health, Underserved pregnant women, Inter-professional collaboration

Posted Date: March 23rd, 2020

DOI: https://doi.org/10.21203/rs.3.rs-17811/v1

License: (c) (1) This work is licensed under a Creative Commons Attribution 4.0 International License. Read Full License 


\section{Abstract}

Objectives: Data on barriers and facilitators to prenatal oral health care among low-income US women are lacking. The objective of this study was to understand barriers/facilitators and patient-centered mitigation strategies related to use of prenatal oral health care among underserved US women.

Methods: We used community-based participatory research to conduct two focus groups with eight pregnant/parenting women; ten individual in-depth interviews with medical providers, dental providers and community/social workers; and one community engagement studio with five representative community stakeholders in 2018-2019. Using an interpretive description research design, we conducted semi-structured interviews and focus groups, which were audio-recorded, transcribed, and analyzed for thematic content.

Results: We identified individual and systemic barriers/facilitators to utilization of prenatal oral health care by underserved US women. Strategies reported to improve utilization included healthcare systemwide change to promote inter-professional collaborations, innovative educational programs to improve dissemination and implementation of prenatal oral health care guidelines, and specialized dental facilities providing prenatal oral health care to underserved groups. Furthermore, use of smartphones offers an innovative entry point to promote utilization of prenatal oral care at the individual level.

Conclusions for practice: Low-income women face multiple, addressable barriers to receipt of oral health care during pregnancy. Inter-professional collaboration holds strong promise for improving prenatal oral health care utilization.

\section{Introduction}

Despite the well-documented association between poor maternal oral health and both preterm/low-birthweight deliveries [1, 2] and increased tooth decay in children after birth [3], many mothers-to-be do not receive timely oral health care [4]. Although recommendations for prenatal oral care have been widely disseminated in the US at both the state [5] and national level[6], utilization remains low. While $76 \%$ of expectant women reported oral health problems during pregnancy, $43 \%$ of US pregnant women have not had a dental checkup [7]. Dental care utilization during pregnancy is even lower among African American women [8], ethnic minorities [9], and women with socioeconomic impediments [10]. Thus, prenatal oral health represents an important, but often-neglected health disparity [11, 12]. Understanding factors that enable or hinder the use of prenatal dental care is crucial to identify effective strategies to promote oral health in pregnant women.

At the patient level, demographic, socioeconomic, psychological, and behavioral factors affect utilization of prenatal dental care. Among women living in California, a population-based research study found that the primary reason for non-receipt of dental care was lack of perceived need, followed by financial barriers [4]. A survey among 625 women (a predominantly Caucasian population of relatively high socioeconomic status) living in Johnson County, lowa, revealed that increased prenatal dental visits were 
associated with being married, having more frequent dentist visits when not pregnant, having dental insurance, and knowledge of the possible connection between oral health and pregnancy outcomes [13]. Similar effects have been reported globally: Australian [14, 15] and Iranian pregnant women [16] reported that the barriers to utilization of prenatal dental care utilization included lack of knowledge, false beliefs, cost, fear, the limited number of dentists providing care to pregnant women, and inadequate recommendations from health professionals.

At the clinician level, recommending prenatal oral healthcare utilization is not routinely practiced by maternity providers $[17,18]$. A national survey [19] among 366 US primary care physicians (PCPs) showed that $37 \%$ of PCPs rarely/never provide oral health counseling to their pregnant patients. Being a female PCP, receipt of continuing education on oral health-related topics, perceived preparedness to provide oral health counseling, and counseling adults with other health conditions contribute to increased prenatal oral health counseling [19]. Moreover, the midwives in Australia reported their reluctance to discuss oral health with pregnant women being unawareness of the possible impact of poor oral health on maternal and child health, and lack of appropriate referral pathways to Public Dental Services [20].

Similar data on barriers and facilitators to prenatal oral health care among low-income US women are lacking. Given differences in cultural beliefs, social environments, and health care systems, it is challenging to generalize findings from other populations to women receiving care in underserved settings in the US. To address this gap, we used community-based participatory research (CBPR) [21] to assessed perceptions, barriers and facilitators, and patient-centered mitigation strategies related to use of prenatal oral health care by underserved US women and a cohort of medical/dental providers and community/social workers. Qualitative analysis of data used an interpretive description research design with triangulation across multiple data sources.

\section{Methods And Materials}

\section{Study Design}

We used the Interpretive Description [22] research design, which is best suited to research problems that are rooted in clinical practice. We examined a clinical phenomenon (limited utilization of prenatal oral health care) to identify themes and patterns related to reported perceptions of oral health care among underserved women, medical/dental providers and community/social workers. This design is useful for research to develop a coherent professional narrative that informs clinical practice and promotes the practice or policy change. Throughout the study, we applied the principle of respectreflexivity to build a trustful relationship between study participants and study personnel, based on the strategies of Paterson . This study was approved by the institutional IRB (RSRB72596). We included all points in a checklist of COREQ guidelines [24] for reporting focus groups and interviews.

\section{Research Settings and Procedure}

\section{Study Site}


This study was conducted in 2018-2019 in Rochester, NY. Rochester is the third most populous city in New York State, with a population of 208,046 residents. We collaborated with two local organizations (University of Rochester and Healthy Baby Network) during development of the study design, participant recruitment, and data collection and interpretation. The University of Rochester is one of the major medical entities in Rochester that provide obstetric services to more than 4,000 pregnant women per year (approximately 40\% African American, $40 \%$ Caucasian, and $20 \%$ others). Three-quarters of these pregnant women benefit from state-supported medical insurance that is provided to low-income groups. The Healthy Baby Network is a Rochester based non-profit social service organization dedicated to improving the health and well-being of mothers and babies by addressing the systemic barriers that cause racial health disparities and prevent healthy births. The Healthy Baby Network provides outreach services to over 200 low-income pregnant women per year.

\section{Eligibility and Recruitment}

To be eligible, all study participants needed be to 18 years of age or older. Five types of informants were included. The pregnant or parenting women who participated needed to be pregnant or have at least one child <2 years of age, and be eligible for state-supported insurance (e.g. Medicaid, Blue Choice, MVP Option). The medical providers, dental providers and community/social workers who participated were required to be currently practicing. The fifth group of informants were community stakeholders purposefully selected by the community studio organizer (see below).

Subjects who had decisional impairment or were incapable of making an informed decision about participation in the study were excluded. Recruitment was conducted by face-to-face study introduction by two trained research coordinators, supplemented by word-of-mouth communication. Study participants were purposefully identified and given a consent form to review and ask questions about, prior to the beginning of study activities. Community stakeholders did not require formal consent, in accordance with standard community studio practice.

\section{Focus Group Discussion}

Two 2-hour focus groups were conducted among eight pregnant or parenting women, using a semistructured interview guide (Appendix 1). We asked the women about their experiences and perceptions of obtaining oral health care during pregnancy, and perceptions about promoting women's oral health. The focus group discussions were conducted in private rooms, at locations convenient for participants. A research assistant took notes and audio recorded all focus groups.

\section{Individual Interview}

Ten 60-minute semi-structured individual interviews were conducted by a trained facilitator and included four community/social workers, three medical providers and three dental providers. Using a semistructured interview guide (Appendix 1), we asked questions that addressed perceptions about barriers and facilitators that are associated with utilization of prenatal oral health care, and perceptions about 
promoting women's oral health. The interviews were conducted in private rooms, as were done for the focus groups, with a research assistant taking notes and making audio recordings.

\section{Community Engagement Studio}

Following the completion of focus groups, individual interviews, and initial data analysis, we conducted a 2-hour Community Studio among five representative community stakeholders to gather their opinions on our initial summary of barriers and facilitators to prenatal utilization of oral health care. The Community Studio method, developed at Vanderbilt, assembles community representatives to provide input into research [25]. Community stakeholders' suggestions were elicited and incorporated into the final data analysis.

\section{Data Analysis}

Audio recordings were initially transcribed by the Temi (USA) transcription service, and further verified by two trained research personnel. Transcribed data were stored and analyzed using MAXQDA software (VERBI GmbH, Berlin, Germany). The data were coded with predetermined and later modified open codes using a codebook (Appendix 2). Thematic content was further analyzed using categorizing and contextualizing strategies to understand the factors associated with utilization of prenatal oral health care among underserved women.

\section{Results}

\section{Sample}

The focus group of pregnant and parenting women were 27 to 32 years of age, with a mean age of 28.4 years. The individual interviews were completed with four social workers, three medical providers (one PCP and two OBGYN), and three dental providers (one hygienist and two community dentists). All participants were female, 34 to 63 years of age, with a mean age of 47.9 years. We reached data saturation by the end of study, when we were no longer receiving new information from additional interviewees.

\section{Women's Experiences of Oral Health Problems During Pregnancy}

The focus group of pregnant and parenting women repeatedly reported experiencing dental problems during pregnancy. Many reported not knowing the importance of maintaining good oral health during pregnancy and described seeking dental care during pregnancy as "frustrating" and "did not know it's needed".

Parenting woman: "I had issues with my gums, probably at mid pregnancy, it started swelling, bleed and hurt. But I didn't go to the dentist. I just kind of dealt with it."

\section{Barriers and Facilitators}


Comments from all five types of informants were categorized as barriers, facilitators, and strategies or implications for policy-making. Table 1 illustrates the representative quotations. Table 2 summarizes the themes from our analysis of participant comments, separated into identified individual and system-level factors.

\section{Individual-level barrier theme 1 - Socioeconomic hardships and competing interests}

A commonly recognized barrier to medical care utilization, socioeconomic hardships, and competing interests, also represents a barrier to utilization of prenatal oral health care. Pregnant/parenting women reported that they could not get to their dental appointments due to lack of babysitting, lack of transportation, and priority of other life events.

\section{Individual-level barrier theme 2 - Lack of awareness of benefits and importance}

Another barrier is unawareness of the benefits and importance of prenatal oral health care among pregnant women. Many pregnant/parenting women reported rarely knew the association between poor oral health and adverse birth outcomes, and the importance of maintaining oral health during pregnancy.

\section{Individual-level barrier theme 3 - Lack of awareness of dental coverage from medical insurance}

A unique barrier identified is unawareness of dental coverage from medical insurance. A majority of the medical providers, community/social workers, and pregnant/parenting women did not know about the dental coverage by the Medicaid insurance. In addition, they were not familiar with the source of dental clinics that accept Medicaid insurance.

\section{System-level barrier theme 1 - Inadequate inter-professional collaboration}

Intriguingly, all participating medical providers, dental providers, community/social workers, and pregnant/parenting women recognized insufficient inter-professional collaboration in promoting prenatal oral health. A majority of the informants acknowledged that the initial introduction of the importance of prenatal oral health should come from medical providers.

\section{System-level barrier theme 2 - Lack of awareness of prenatal oral health guidelines}

We identified another system-level barrier as unawareness of the latest practice guidelines among medical, dental providers, and community/social workers. Although some of them knew certain types of prenatal oral health guidelines, none of them were aware of the latest practice guidelines and the recommendations from professional organizations, such as the American College of Obstetricians and Gynecologists or the American Dental Association, both of which clearly state that conditions that require immediate treatment, such as examinations, extractions, root canals, and restorations are important and safe to perform at any time of the pregnancy [26]. Some OBGYNs said they continue receiving requests form dental providers of their pregnant patients for medical clearance to initiate dental treatment. This unfamiliarity of the guideline was echoed by other participating dentists, who reported avoiding providing 
dental treatment to women during their 1st trimester, for which the ACOG and ADA recommend as a safe period for receiving dental care.

\section{System-level barrier theme 3 - Insufficient dentists providing treatment to underserved pregnant women}

Both medical providers and community/social workers reported that they had referred patients for dental care, but unfortunately, some of their patients were denied dental care due to the pregnancy. Furthermore, the pregnant/parenting women expressed that limited dental clinics accepting their insurance and the long waiting lists exacerbated their unwillingness to visit a dentist during pregnancy.

\section{Facilitators}

\section{Individual-level facilitator theme 1 - Constant reminders}

A critical facilitator that pregnant/parenting women proposed was "constant reminders." Participating women stressed the importance of these reminders, which should be introduced by their maternal doctors as early as their first pregnancy visit, and repeated at their follow-up pregnancy appointments.

\section{Individual-level facilitator theme 2 - Raise community awareness via mass media}

Pregnant/parenting women suggested raising community awareness via mass media as an essential facilitator to improve the use of prenatal oral care. They recommended the use of commercials, campaigns, bus stop advertisements, health fairs, and community events.

\section{System-level facilitator theme 1 - Strengthen interprofessional collaboration}

Strengthening interprofessional collaboration was proposed as a strong facilitator to promote the use of prenatal oral health care. The medical, dental providers and community/social workers specifically commented on several pivotal points that are crucial to a sustainable interprofessional collaboration, including merging the medical and dental electronic record systems, shortening physical distance between prenatal medical and dental offices, creating billable prenatal oral health counseling services, and enhancing collaborations with social service groups.

\section{Innovative Entry Points for Prenatal Oral Health Care Promotion}

Through this study, we furthered mapped the elements of real and virtual community with which women interact during pregnancy, demonstrated in Figure 1. The map reveals the potential entry points through which we can promote prenatal oral health to the majority of the underserved pregnant women. These include traditional medical contacts through maternal providers; traditional social circles such as community groups, family and friends; social benefit support groups; children's community circles (e.g. daycare), and social workers. What stands out as an innovative entry point is the virtual community, through which social media and smartphone apps can spread information. 
Parenting woman: "Nowadays, most people will use smartphones. Smartphone will be a good way for patient to get oral health information. For example, if they are pregnant or breastfeeding, they can download an app with professional dental knowledge plugin at every different stage. When they are reviewing pregnancy or breastfeeding related information, noticeable pictures and videos will provide better oral health education, not only for moms, but also for young children."

Parenting woman: "It should be a commercial somewhere, whether it's Facebook and it could be played between a popular show that everyone is watching."

OBGYN: "Many of our moms are members of online support groups. I think Text-for-Baby is one that connects moms with knowledge they need to know during pregnancy."

\section{Discussion}

In recent years, federal agencies and professional organizations have mounted a large effort to address an increasingly recognized public health problem, poor prenatal oral health, which has serious implications for maternal and child health. Yet, prenatal oral health care is significantly underutilized in the US (and worldwide), especially among the underserved group.

This study used underserved pregnant women and clarified barriers and facilitators to their use of prenatal oral health care. We applied the principle of respectreflexivity to build a trustful relationship between study participants and study personnel. , we used rigorous qualitative methods to promote validity, in particular triangulation across different data collection methods and different stakeholders. Finally, we identified barriers and facilitators that led to the identification of several innovative strategies and indications for potential policy-making regarding prenatal utilization of oral health care in the community.

Based on our study, we share below four recommendations that have potential to improve prenatal oral health care utilization in underserved US women.

1. Create healthcare system-wide change to promote inter-professional collaborations

Incorporate dental care into the medical care setting. To address the historical problem of inadequate communication between medical and dental providers, collaborations could be facilitated through a shared facilities and particularly electronic record systems. Referrals, reminders, and feedback that could be easily communicated on a shared platform would significantly improve the rate of follow-through for recommended prenatal oral health care.

Promote prenatal oral health counseling by non-MDs. Within the scope of prenatal oral health, the professionals who could make significant impact changes include non-MD providers, e.g., midwives [27], nurse practitioners, the Centering Pregnancy Prenatal Care group [28] and medical technicians. To maintain sustainability, billable prenatal oral health counseling services provided by non-dental providers should be developed. 
Improve collaborations with social benefitprograms, e.g., Women, Infant and Children (WIC). Use innovative mediators to promote prenatal oral health, such as community/social workers, peer counselors and doulas.

\section{Introduce innovative educational programs to improve dissemination and implementation of} prenatal oral health care guidelines

A majority of the medical/dental providers and community social worker participants were unaware of the current prenatal oral health care guidelines, so the first step should be to increase the awareness of guidelines. Lee et al investigated to what extent dentists adopted perinatal care practice guidelines [29] and found that correct knowledge about the appropriateness of routine services and emergency procedures for pregnant patients is essential for adherence to practice guidelines [29]. The second step is to identify guidelines implementation strategies to change practice patterns. As Bahrami et al noted, no one implementation strategy is a panacea and few studies have investigated their effectiveness in dentistry [30]. Innovative continuing education programs are critically needed to address this gap.

\section{Develop specialized dental facilities to provide prenatal oral health care to underserved groups.}

Use a Hub-Spoke model, highly specialized dental facilities that are dedicated to underserved pregnant women could serve as the hub to meet regional patients' needs and educate staff at satellite facilities. The Eastman Institute for Oral Health (EIOH) at the University of Rochester has robust clinical services with a strong community orientation. The most significant recent change to the current prenatal oral care services in Rochester has been the new ElOH Pregnancy and Infant Dental clinic, which is dedicated to underserved pregnant women and their infants.

4. Use social media and smartphones to promote prenatal oral health education and oral health care utilization.

Smartphone health care products have been successfully applied in managing individual behaviors and health conditions [31], such as smoking cessation, weight loss, medication adherence, and Parkinson's disease progression monitoring $[31,32]$ to name a few. With $77 \%$ of Americans owning a smartphone [33], a smartphone app offers a potentially high impact way to provide prenatal oral health interventions. Although there are a plethora of apps available to help expectant mothers anticipate and manage the physical and mental effects of pregnancy, none are available that specifically address pregnancy and oral health. Such an app has substantial potential to help educate pregnant mothers and engage them in the management of their own oral health and hygiene, as well as providing a critically needed source of information on available dental clinics and insurance.

Despite the strengths of this study, our findings need to be cautiously interpreted. First, all study participants in the cohort of medical, dental providers and community/social workers were female, which precludes the generalization of our findings to male clinicians or community/social workers. Second, the study was conducted in only one city. In the US, despite the extended Medicaid health insurance coverage 
for pregnant women through public programs, adult dental benefits are optional for states to offer among Medicaid services. As of 2014, seven states provided no dental benefits and only 17 states provided comprehensive adult dental benefits, including New York State [34]. Although insurance coverage was not identified as a barrier in our study, for states where low-income pregnant women lack dental insurance, this represents a major barrier to prenatal utilization of oral health care for disadvantaged women and their infants.

\section{Conclusions}

Low-income women face multiple, addressable barriers to receipt of oral health care during pregnancy. Inter-professional collaboration holds strong promise for improving prenatal oral health utilization. System-wide policy changes to improve such inter-professional collaboration should include explicit recommendations for prenatal oral health care from obstetrical/medical providers, effective mediation by community/social workers, and universal practice of guideline implementation by community dental providers. Furthermore, use of smartphones and social media offers an innovative entry point to promote prenatal oral care utilization at the individual level. We plan to test the effectiveness of these innovative strategies in our future studies.

\section{Abbreviations}

PCP Primary care physicians

CBPR Community-based participatory research

IRB Institutional Review Board

OBGYN Obstetrician and gynecologist

\section{Declarations}

\section{Ethics approval and consent to participate}

The study protocols (RSRB72596) were approved by the University of Rochester Research subject review board. All participants were informed of the study objectives and protocols, and gave written consent prior to study activities.

\section{Consent for publication}

Not applicable.

\section{Availability of data and materials}


The datasets generated and/or analyzed during the current study are not publicly available due to individual privacy but are available from the corresponding author on reasonable request.

\section{Competing interests}

The authors declare that they have no competing interests.

\section{Funding}

The project described in this publication was supported by the University of Rochester CTSA award number UL1TR002001 from the National Center for Advancing Translational Sciences of the National Institutes of Health. The content is solely the responsibility of the authors and does not necessarily represent the official views of the National Institutes of Health. Dr. Xiao's work is supported by National Institute for Dental Craniofacial Research K23DE027412. The funder of the study had no role in in the design of the study, collection, analysis, interpretation of data, and in writing the manuscript.

\section{Author contributions}

LW, KF, SB and JX contributed to the conception, design, data acquisition, analysis, and interpretation, drafting and critically revising the manuscript; MS, ELL, EE, MM, DTK and RJB contributed to the conception, design, data interpretation, and critically reviewing the manuscript; JR contributed to data acquisition, analysis, and interpretation, drafting and critically revising the manuscript; RR and MT contributed to data acquisition, data interpretation and critically reviewing the manuscript. All authors have read and approved the final version of the manuscript and agree to be accountable for all aspects of the work.

\section{Acknowledgements}

We wish to express sincere gratitude to our study participants. We thank Dr. Constance Baldwin for her critics and instructions on the content and writing of the manuscript.

\section{References}

1. Corbella S, Taschieri S, Francetti L, De Siena F, Del Fabbro M: Periodontal disease as a risk factor for adverse pregnancy outcomes: a systematic review and meta-analysis of case-control studies. Odontology 2012, 100(2):232-240.

2. Puertas A, Magan-Fernandez A, Blanc V, Revelles L, O'Valle F, Pozo E, Leon R, Mesa F: Association of periodontitis with preterm birth and low birth weight: a comprehensive review. J Matern Fetal Neonatal Med 2018, 31(5):597-602.

3. Chaffee BW, Gansky SA, Weintraub JA, Featherstone JD, Ramos-Gomez FJ: Maternal oral bacterial levels predict early childhood caries development. Journal of dental research 2014, 93(3):238-244. 
4. Marchi KS, Fisher-Owens SA, Weintraub JA, Yu Z, Braveman PA: Most pregnant women in California do not receive dental care: findings from a population-based study. Public Health Rep 2010, 125(6):831-842.

5. Health NYSDo: Practice Guidelines: Oral Health Care during Pregnancy and Early Childhood. . In.; 2006.

6. Workgroup OHCDPE: Oral Health Care During Pregnancy: A National Consensus Statement. In. Edited by Washington DNMaCOHRC; 2012.

7. Editorial: Majority of pregnant women have oral health problems, yet $43 \%$ don't seek dental treatment. In: Dentistry IQ. 2015.

8. Thompson TA, Cheng D, Strobino D: Dental cleaning before and during pregnancy among Maryland mothers. Matern Child Health J 2013, 17(1):110-118.

9. Marchi KS, Fisher-Owen SA, Weintraub JA, Yu Z, Braveman PA: Most pregnant women in California do not receive dental care: findings from a population-based study. Public Health Rep 2010, 125(6):831-842.

10. Singhal A, Chattopadhyay A, Garcia Al, Adams AB, Cheng D: Disparities in unmet dental need and dental care received by pregnant women in Maryland. Maternal and child health journal 2014, 18(7):1658-1666.

11. Guarnizo-Herreno CC, Wehby GL: Explaining racial/ethnic disparities in children's dental health: a decomposition analysis. Am J Public Health 2012, 102(5):859-866.

12. Azofeifa A, Yeung LF, Alverson CJ, Beltran-Aguilar E: Oral health conditions and dental visits among pregnant and nonpregnant women of childbearing age in the United States, National Health and Nutrition Examination Survey, 1999-2004. Prev Chronic Dis 2014, 11:E163.

13. Al Habashneh R, Guthmiller JM, Levy S, Johnson GK, Squier C, Dawson DV, Fang Q: Factors related to utilization of dental services during pregnancy. J Clin Periodontol 2005, 32(7):815-821.

14. Lim M, Riggs E, Shankumar R, Marwaha P, Kilpatrick N: Midwives' and women's views on accessing dental care during pregnancy: an Australian qualitative study. Aust Dent J 2018.

15. Riggs E, Yelland J, Shankumar R, Kilpatrick N: 'We are all scared for the baby': promoting access to dental services for refugee background women during pregnancy. BMC pregnancy and childbirth 2016, 16:12.

16. Bahramian H, Mohebbi SZ, Khami MR, Quinonez RB: Qualitative exploration of barriers and facilitators of dental service utilization of pregnant women: $\mathbf{A}$ triangulation approach. $B M C$ Pregnancy Childbirth 2018, 18(1):153.

17. Wilder R, Robinson C, Jared HL, Lieff S, Boggess K: Obstetricians' knowledge and practice behaviors concerning periodontal health and preterm delivery and low birth weight. J Dent Hyg 2007, 81(4):81.

18. George A, Dahlen HG, Reath J, Ajwani S, Bhole S, Korda A, Chok HN, Miranda C, Villarosa A, Johnson $\mathrm{M}$ : What do antenatal care providers understand and do about oral health care during pregnancy: a cross-sectional survey in New South Wales, Australia. BMC Pregnancy Childbirth 2016, 16(1):382. 
19. Byrd MG, Quinonez RB, Rozier RG, Phillips C, Mehegan M, Martinez L, Divaris K: Prenatal Oral Health Counseling by Primary Care Physicians: Results of a National Survey. Maternal and child health journal 2018, 22(7):1033-1041.

20. George A, Johnson M, Duff M, Blinkhorn A, Ajwani S, Bhole S, Ellis S: Maintaining oral health during pregnancy: perceptions of midwives in Southwest Sydney. Collegian 2011, 18(2):71-79.

21. Frerichs L, Lich KH, Dave G, Corbie-Smith G: Integrating Systems Science and Community-Based Participatory Research to Achieve Health Equity. Am J Public Health 2016, 106(2):215-222.

22. Thorne S, Kirkham SR, MacDonald-Emes J: Interpretive description: a noncategorical qualitative alternative for developing nursing knowledge. Res Nurs Health 1997, 20(2):169-177.

23. Paterson BL: A framework to identify reactivity in qualitative research. West J Nurs Res 1994, 16(3):301-316.

24. Tong A, Sainsbury P, Craig J: Consolidated criteria for reporting qualitative research (COREQ): a 32item checklist for interviews and focus groups. Int J Qual Health Care 2007, 19(6):349-357.

25. Joosten YA, Israel TL, Williams NA, Boone LR, Schlundt DG, Mouton CP, Dittus RS, Bernard GR, Wilkins $\mathrm{CH}$ : Community Engagement Studios: A Structured Approach to Obtaining Meaningful Input From Stakeholders to Inform Research. Acad Med 2015, 90(12):1646-1650.

26. American College of $\mathrm{O}$, Gynecologists Women's Health Care P, Committee on Health Care for Underserved W: Committee Opinion No. 569: oral health care during pregnancy and through the lifespan. Obstet Gynecol 2013, 122(2 Pt 1):417-422.

27. Heilbrunn-Lang AY, de Silva AM, Lang G, George A, Ridge A, Johnson M, Bhole S, Gilmour C: Midwives' perspectives of their ability to promote the oral health of pregnant women in Victoria, Australia. BMC Pregnancy Childbirth 2015, 15:110.

28. Adams SH, Gregorich SE, Rising SS, Hutchison M, Chung LH: Integrating a Nurse-Midwife-Led Oral Health Intervention Into CenteringPregnancy Prenatal Care: Results of a Pilot Study. J Midwifery Womens Health 2017, 62(4):463-469.

29. Lee RS, Milgrom P, Huebner CE, Conrad DA: Dentists' perceptions of barriers to providing dental care to pregnant women. Womens Health Issues 2010, 20(5):359-365.

30. Bahrami M, Deery C, Clarkson JE, Pitts NB, Johnston M, Ricketts I, MacLennan G, Nugent ZJ, Tilley C, Bonetti D et al: Effectiveness of strategies to disseminate and implement clinical guidelines for the management of impacted and unerupted third molars in primary dental care, a cluster randomised controlled trial. British Dental Journal 2004, 197(11):691-696.

31. Ernsting C, Dombrowski SU, Oedekoven M, JL OS, Kanzler M, Kuhlmey A, Gellert P: Using Smartphones and Health Apps to Change and Manage Health Behaviors: A Population-Based Survey. J Med Internet Res 2017, 19(4):e101.

32. Wang J, Wang Y, Wei C, Yao NA, Yuan A, Shan Y, Yuan C: Smartphone interventions for long-term health management of chronic diseases: an integrative review. Telemed J E Health 2014, 20(6):570583.

33. Pew Research Center. Mobile Fact Sheet. Feb 5 Uwpof-sm. 
34. State MMCSDANPo, http://www.msdanationalprofile. MCOHPAa, com/. Accessed September 7.

\section{Tables}


Table 1: Illustrative Quotations from Study Informants: Barriers and Facilitators to Prenatal Oral Health Care Utilization

\begin{tabular}{|c|c|c|}
\hline Barriers & Informants & Illustrative Quotations \\
\hline $\begin{array}{l}\text { Socioeconomic } \\
\text { hardships and } \\
\text { competing } \\
\text { interests }\end{array}$ & $\begin{array}{l}\text { Parenting } \\
\text { woman }\end{array}$ & $\begin{array}{l}\text { "I'm not so pressured to figure out dental care for myself, at least not when I have } \\
\text { other things going on that's more important than dental care." }\end{array}$ \\
\hline $\begin{array}{l}\text { Lack of } \\
\text { awareness of } \\
\text { benefits and } \\
\text { importance }\end{array}$ & $\begin{array}{l}\text { Parenting } \\
\text { woman }\end{array}$ & $\begin{array}{l}\text { "I wish I knew more about that my dental health has something to do with my } \\
\text { baby's health." }\end{array}$ \\
\hline $\begin{array}{l}\text { Lack of } \\
\text { awareness of } \\
\text { dental coverage } \\
\text { from medical } \\
\text { insurance }\end{array}$ & $\begin{array}{l}\text { Social } \\
\text { worker }\end{array}$ & $\begin{array}{l}\text { "The population we serve has Medicaid insurance which is comprehensive. But I'm } \\
\text { not sure that it's clear to the patients that it includes dental coverage." }\end{array}$ \\
\hline $\begin{array}{l}\text { Inadequate } \\
\text { inter- } \\
\text { professional } \\
\text { collaboration }\end{array}$ & $\begin{array}{l}\text { Parenting } \\
\text { woman } \\
\text { Parenting } \\
\text { woman }\end{array}$ & $\begin{array}{l}\text { "My provider never told me that was a problem. I started having bleeding gums } \\
\text { and then I looked it up online. That's how I know about it." } \\
\text { "It would be good if the OB would address this. Have you seen your dentist? That } \\
\text { would be one way to make pregnant women go see the dentist." }\end{array}$ \\
\hline $\begin{array}{l}\text { Lack of } \\
\text { awareness of } \\
\text { prenatal oral } \\
\text { health } \\
\text { guidelines }\end{array}$ & DDS/DMD & $\begin{array}{l}\text { "Some patients worry about dental treatment during pregnancy. Currently, we just } \\
\text { give patient verbal education, no handouts, we just tell patient due to the hormone } \\
\text { change, you need to have better oral hygiene. If there is a guideline that we can } \\
\text { show them, it is better." } \\
\text { "In medical school, we didn't have classes for oral health. None." }\end{array}$ \\
\hline $\begin{array}{l}\text { Insufficient } \\
\text { dentists } \\
\text { providing } \\
\text { treatment to } \\
\text { underserved } \\
\text { pregnant women }\end{array}$ & $\begin{array}{l}\text { Parenting } \\
\text { woman }\end{array}$ & $\begin{array}{l}\text { "The worst thing of being pregnant is you have toothache. So I'm just going to be } \\
\text { honest with you. I had a bad tooth, I was in a lot of pain, but they (dentists) would } \\
\text { not pull it because I was pregnant. I had to go to another doctor, acted like I } \\
\text { wasn't pregnant and they pulled the tooth out." } \\
\text { "Oftentimes what comes into play is no one (dentists) will see them (pregnant } \\
\text { women). They (patients) told me, they are in too much pain, but the dentists won't } \\
\text { do anything, they will ask me can you do something?" }\end{array}$ \\
\hline Facilitators & Informants & Illustrative Quotations \\
\hline $\begin{array}{l}\text { Constant } \\
\text { reminders }\end{array}$ & $\begin{array}{l}\text { Parenting } \\
\text { woman }\end{array}$ & $\begin{array}{l}\text { "I need constant reminders by my OB. When I find out I'm pregnant, that could be } \\
\text { a good time to be asked, hey, do you know this will cause problem to your baby? } \\
\text { Then, when I go to my next appointment, they ask me, hey, here's some more } \\
\text { information about this, the germs in your mouth could be passed to your baby. } \\
\text { When I go to my next appointment, I will be asked again, hey, I don't know if you } \\
\text { took a look at that paperwork? A constant reminder goes a long way." }\end{array}$ \\
\hline $\begin{array}{l}\text { Raise } \\
\text { community } \\
\text { awareness via } \\
\text { mass media }\end{array}$ & $\begin{array}{l}\text { Parenting } \\
\text { woman }\end{array}$ & $\begin{array}{l}\text { "It (prenatal oral health education) has to be interesting, I would say more of a } \\
\text { commercial on TV. Whether I'm eating, or I'm talking on the phone, my eyes are } \\
\text { still on TV. I can read what's on the TV, that's going to be in my mind. Even if I } \\
\text { don't hear nothing about what they're saying, I'm, at least, going to remember } \\
\text { something from that commercial." }\end{array}$ \\
\hline $\begin{array}{l}\text { Strengthen } \\
\text { interprofessional } \\
\text { collaboration }\end{array}$ & PCP & $\begin{array}{l}\text { "Adding an additional task to an already packed prenatal schedule for medical } \\
\text { providers can be challenging. But I think our midwifery colleagues are a bit } \\
\text { flexible and they often do some more holistic family care. For example, they make } \\
\text { home visits in the neonatal period. Introducing the idea of oral health in that } \\
\text { community might be reinforcing." }\end{array}$ \\
\hline
\end{tabular}


OBGYN

"The system for EPIC, I do not think is yet to set up having special health maintenance tabs for pregnancy. But if there was, you could have a health maintenance checklist that says, dental care is overdue or is unsatisfied at this time. That would be a reasonable thing to consider for all pregnant patients."

"OBGYN, family doctors or pediatricians giving oral health education, potentially, DDS/DMD depends on what is involved to satisfy that billing code."

"The social workers are also very important for spreading correct oral health knowledge for pregnant women. They can work as a bridge to help mothers getting OBGYN sufficient dental education and dental care in community."

"There is a push currently to offer doula services to a broader range of patients. I think expand Medicaid coverage to cover doulas for lower income populations, who are oftentimes going out to the community to support. So that would be another place to introduce oral health education during pregnancy." 


\section{Table 2. Summary of Barriers, Facilitators, Strategies and Implacations for Policy- Making}

Factors

Barriers
Facilitators

Strategies and implications for policymaking

Individual level

Socioeconimic hardships

1. lack of babysitting

2. lack of transportation

Competing interest

Lack of awarenss of benefits \& importance

Lack of awarenss of dental coverage from statesupported medical insurance

\section{System level}

Inadequate interprofessional collaboration
Advocacy by medical providers \& social/community workers about the importance of prenatal oral health
Receive "constant" reminders [actual reminders from health care navigators and virtual reminders from mobile phone device (e.g., texting, smartphone app)

Receive prenatal oral health education and dental resources information on clinic resources and insurance coverage through smartphone device (social media, app)

Community-wide dissemination via mass media (e.g.,TV commercials) of the benefits \& importance of prenatal oral health and dental insurance coverage,
Use social media and smartphone device to promote prenatal oral health education and oral health care utilization.
Create healthcare system-wide change to promote interprofessional collaborations - Incorporate dental care into the medical care setting: shared physical location \& shared electronic record system

- Promote prenatal oral health counseling by non-MDs, e.g., nurse practitioners, midwives, medical technicians, and social workers. Billable prenatal oral health counseling service provided by medical providers \& staff.

- Improve collaborations with social benefit programs (e.g., WIC), use innovative mediators to promote prenatal oral health, e.g., Doula, peer councilors

Introduce innovative educational program to improve prenatal oral health care guidelines dissemination and implementation among medical/dental providers and community/social workers

Develop specialized dental facilities providing prenatal oral health care to underserved groups, Hub-Spoke model dentists providing treatment to underserved pregnant women 


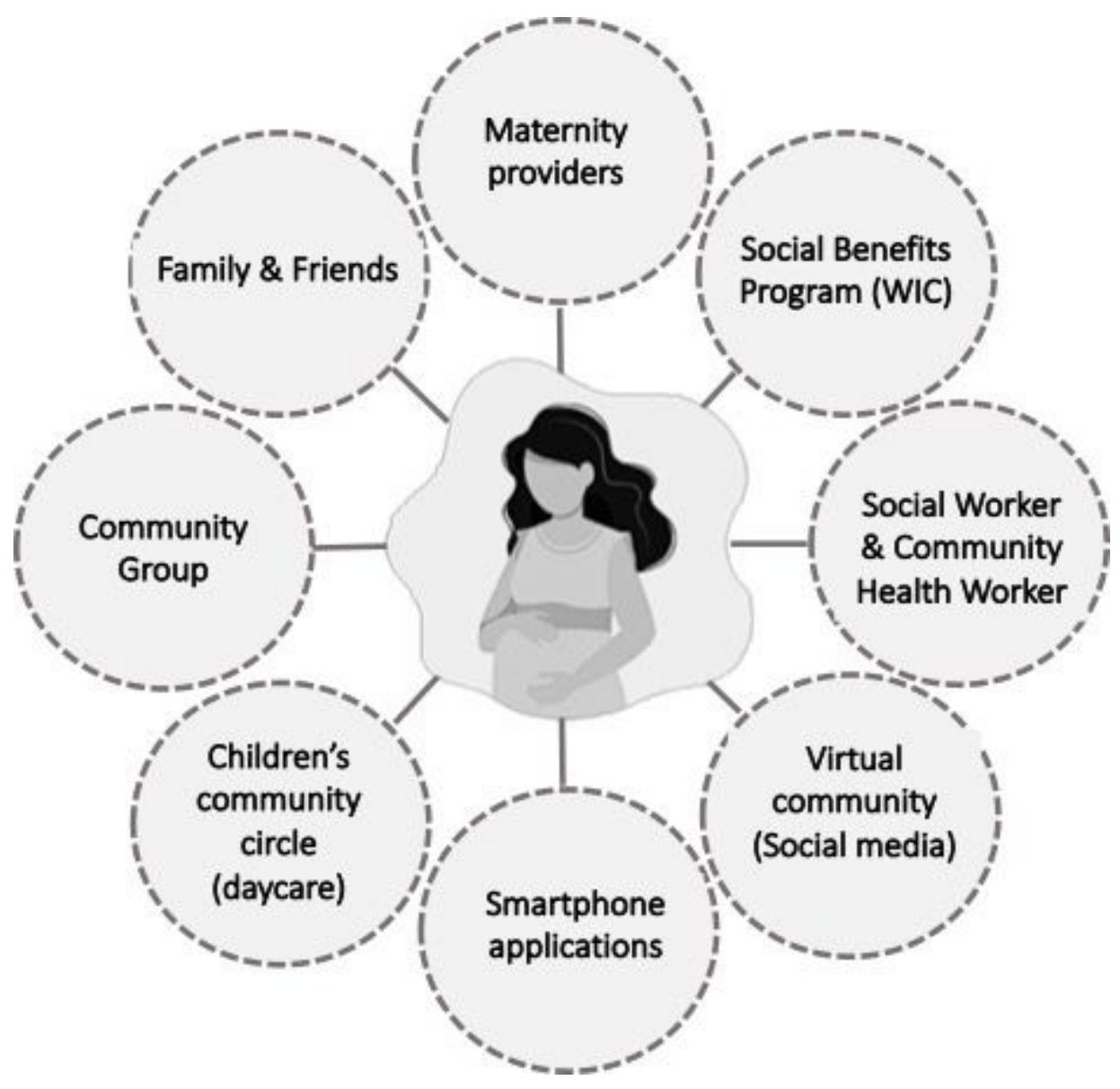

Figure 1

Entry point for promoting prenatal oral health care *WIC, Women, Infants and Children, is a federal assistance program of the Food and Nutrition Service (FNS) of the United States Department of Agriculture (USDA) for healthcare and nutrition of low-income pregnant women, breastfeeding women, and children under the age of five.

\section{Supplementary Files}

This is a list of supplementary files associated with this preprint. Click to download.

- Appendix1and2.docx 